\title{
Control of Crystal Size and Morphology of Calcium Carbonate Crystal Polymorphism
}

\author{
Wakana Nagaki ${ }^{1}$, Norihito Doki ${ }^{*}$, Masaaki Yokota1, Kazuo Yamashita ${ }^{2}$, \\ Toshiji Kojima², Toshiyuki Tanaka² \\ ${ }^{1}$ Department of Chemistry and Bioengineering, Faculty of Engineering, Iwate University, Morioka, Japan \\ ${ }^{2}$ OKUTAMA KOGYO CO., LTD., Tokyo, Japan \\ Email: *doki@iwate-u.ac.jp
}

How to cite this paper: Nagaki, W., Doki, N., Yokota, M., Yamashita, K., Kojima, T. and Tanaka, T. (2021) Control of Crystal Size and Morphology of Calcium Carbonate Crystal Polymorphism. Journal of Materials Science and Chemical Engineering, 9, 38-45.

https://doi.org/10.4236/msce.2021.94005

Received: January 5, 2021

Accepted: April 22, 2021

Published: April 25, 2021

Copyright $\odot 2021$ by author(s) and Scientific Research Publishing Inc. This work is licensed under the Creative Commons Attribution International License (CC BY 4.0).

http://creativecommons.org/licenses/by/4.0/

\begin{abstract}
Calcium carbonate, the main component of lime, has been widely used in industry due to its stability and economy. Calcium carbonate has three types of crystalline polymorphism, calcite, aragonite and vaterite, each with different properties. Therefore, the control of crystal polymorphism is required for industrial applications. In addition, the control of crystal size and shape is similarly required for different applications. In this study, the effect of $\mathrm{SrCO}_{3}$ on the size control of fine aragonite-type calcium carbonate crystals by uniform urea precipitation and the effect of $\mathrm{SrCO}_{3}$ addition was investigated by adding solid strontium carbonate and dissolved strontium carbonate. The addition of solid strontium carbonate affected the crystal polymorphism and size of the calcium carbonate produced, depending on the properties of the solid particles and the amount of $\mathrm{SrCO}_{3}$ added. Experiments on the addition of dissolved $\mathrm{SrCO}_{3}$ showed that the supersaturation formation rate could be controlled to control the crystal polymorphism.
\end{abstract}

\section{Keywords}

$\mathrm{CaCO}_{3}$, Aragonite, $\mathrm{SrCO}_{3}$, Crystal Polymorphism, Size Control

\section{Introduction}

Limestone is one of the few mineral resources that are self-sufficient in the country, and veins of limestone, the raw material of limestone, are scattered throughout the country. Calcium carbonate $\left(\mathrm{CaCO}_{3}\right)$, the main component of limestone, has good stability and economy and is widely used industrially in rubber, plastics, paints, and paper-making. The industrially used $\mathrm{CaCO}_{3}$ is classified into two types: ground calcium carbonate (GCC), which is made by finely 
grinding natural lime, and precipitated calcium carbonate (PCC), which is produced through chemical synthesis. GCC is produced by the crushing and classifying process and has irregular particle size and shape, while PCC is mainly produced by the lime milk coal oxidation method, in which calcium carbonate is precipitated by blowing $\mathrm{CO}_{2}$ into calcium hydroxide slurry. Other methods of PCC include the sodium carbonate lime method and the calcium nitrate-ammonium carbonate method. Calcium carbonate has three crystalline polymorphs: calcite, aragonite, and vaterite [1] [2] [3].

Thermodynamically, calcite is the most stable, and calcite is the main component of limestone. Aragonite is stable at room temperature and pressure, but it is easily transferred to calcite when heat or pressure is applied. For this reason, calcite transferred from aragonite is often found in fossils. Vaterite is the most unstable and easily transfers to aragonite and calcite under ambient temperature and pressure. Thus, it is desirable to control the crystal polymorphism of calcium carbonate according to the application because it shows different physical properties depending on the crystal polymorphism.

Therefore, the control of crystal polymorphism by various methods has been studied [4]-[9]. The polymorphism of calcium carbonate crystal is also affected by the additives [6] [7]. For example, it has been reported that the addition of metal ions to the reaction system stabilizes aragonite by $\mathrm{Ni}^{2+}$ addition, $\mathrm{Mg}^{2+}$ promotes the transition to calcite, and $\mathrm{Fe}^{3+}$ stabilizes the satellite [8]. In addition, calcium carbonate polymorphism is affected by the polymorphism present in the reaction system. When calcium bicarbonate saturated solution contains a small amount of calcite, the product is $100 \%$ calcite, and when a small amount of aragonite is present, only aragonite is obtained. In industrial applications, it is also desirable to control the size and morphology of the crystals according to the application. For example, fine crystals of $\mathrm{CaCO}_{3}$ and crystals with large specific surface areas have the effect of increasing the strength of rubber and the glossiness of paper when added. In the past, most of the PCC used calcite, but recently, columnar aragonite has been attracting attention as a paper coating pigment. Columnar calcium aragonite has good dispersibility in water. In addition, it has good flowability in a high particle density slurry state, improves the whiteness and opacity of coated paper, and shows good printing characteristics due to its good lubrication of the coated paper surface.

The purpose of the study was to control particle size of fine aragonite-type calcium carbonate crystals by uniform urea precipitation and to clarify the effect of $\mathrm{SrCO}_{3}$ addition. Furthermore, the effect of $\mathrm{SrCO}_{3}$ addition was investigated in detail by using two kinds of $\mathrm{SrCO}_{3}$, one is solid $\mathrm{SrCO}_{3}$ and another is dissolved $\mathrm{SrCO}_{3}$.

\section{Experimental}

\section{1. $\mathrm{CaCO}_{3}$ Crystallization Experiments in the Presence of Solid $\mathrm{SrCO}_{3}$}

The crystallization tank with a $500 \mathrm{~mL}$ interference plate contained $200 \mathrm{~mL}$ of 1 
mol/L aqueous urea solution and a $300 \mathrm{~mL}$ beaker contained $200 \mathrm{~mL}$ of 0.4 $\mathrm{mol} / \mathrm{L}$ aqueous $\mathrm{Ca}\left(\mathrm{NO}_{3}\right)_{2}$ solution, and the two solutions were heated; when the temperature reached $80^{\circ} \mathrm{C}$, the aqueous solution was added to the aqueous urea solution in the crystallization tank, where $\mathrm{SrCO}_{3}$ was added simultaneously. The amount of $\mathrm{SrCO}_{3}$ added was advanced at $2.95 \times 10^{-3}, 7.38 \times 10^{-3}, 2.95 \times 10^{-2}$, $7.38 \times 10^{-2}$ and $2.95 \times 10^{-1}(\mathrm{~g} / 100 \mathrm{~mL})$. Three types of $\mathrm{SrCO}_{3}$ with different particle sizes were used for the addition.

The mixture was kept at $80^{\circ} \mathrm{C}$ and stirred at $300 \mathrm{rpm}$ for $4 \mathrm{~h}$ with a stirring blade, and the resulting crystals were filtered, washed and dried and shown in Figure 1. The average grain size and aragonite content of the obtained crystals were evaluated. The average size was determined from the size distribution measured by optical microscope images. Aragonite content was calculated using calibration curve after PXRD measurement of the product crystals. In addition, elemental analysis was performed by EDX.

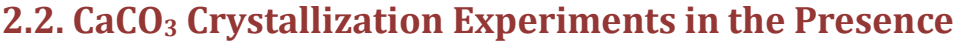 of Dissolved $\mathrm{SrCO}_{3}$}

The $\mathrm{CaCO}_{3}$ crystallization experiments during the addition of solid $\mathrm{SrCO}_{3}$ were a process involving the dissolution of $\mathrm{SrCO}_{3}$. Therefore, the effect of solid $\mathrm{SrCO}_{3}$ was avoided and $\mathrm{CaCO}_{3}$ was prepared by adding dissolved $\mathrm{SrCO}_{3}$ and its effect was investigated. $\mathrm{SrCO}_{3}, 2.3 \mathrm{~g}(0.022 \mathrm{~mol})$ was added to $50 \mathrm{~mL}$ of $1 \mathrm{M} \mathrm{HNO}_{3}$ solution to prepare dissolved $\mathrm{SrCO}_{3} .150 \mathrm{~mL}$ of $1 \mathrm{~mol} / \mathrm{L}$ aqueous urea solution was heated in a $500 \mathrm{~mL}$ crystallizer with a $500 \mathrm{~mL}$ interfering plate. $200 \mathrm{~mL}$ of 0.4 $\mathrm{mol} / \mathrm{L}$ aqueous $\mathrm{Ca}\left(\mathrm{NO}_{3}\right)_{2}$ solution and $50 \mathrm{~mL}$ of dissolved $\mathrm{SrCO}_{3}$ solution were heated to When the temperature reached $80^{\circ} \mathrm{C}$, three aqueous solutions were mixed in the crystallizer, at which time $\mathrm{Ca}\left(\mathrm{NO}_{3}\right)_{2}$ and dissolved $\mathrm{SrCO}_{3}$ were added at six different rates. The mixture was kept at $80^{\circ} \mathrm{C}$ and stirred at $300 \mathrm{rpm}$ with a stirring blade, and the crystals obtained in a total of 4 hours were filtered, washed and dried and shown in Figure 1.

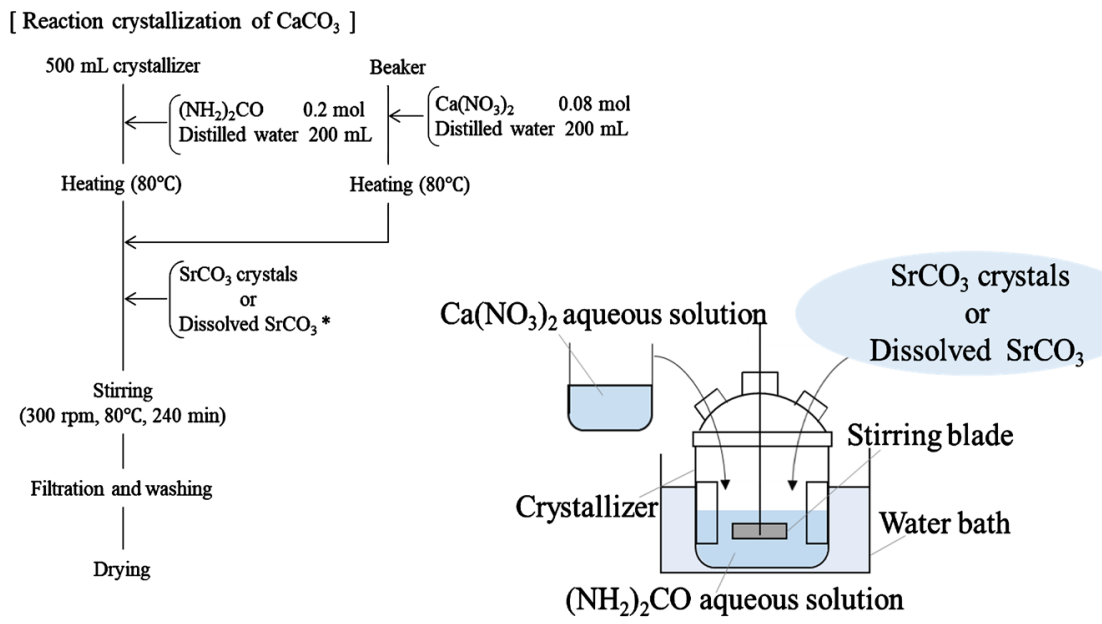

Figure 1. Schematic diagram of experimental setup. 


\section{Results and Discussion}

\subsection{Effect of Adding $\mathrm{SrCO}_{3}$}

Crystallization experiments were conducted under a total of 15 conditions using $0.3 \mu \mathrm{m}, 30 \mu \mathrm{m}$, and $100 \mu \mathrm{m}$ solid $\mathrm{SrCO}_{3}$, with the addition of $2.95 \times 10^{-3}, 7.38 \times$ $10^{-3}, 2.95 \times 10^{-2}, 7.38 \times 10^{-2}$ and $2.95 \times 10^{-1}(\mathrm{~g} / 100 \mathrm{~mL})$. Optical microscopic images of crystallized $\mathrm{CaCO}_{3}$ are shown in Figure 2. Columnar crystals were obtained. As the amount of strontium carbonate was increased and the particle size of strontium carbonate was decreased, the size of the crystals became smaller. Under the present conditions, the $\mathrm{SrCO}_{3}$ crystals are completely dissolved in the solution when 0.00295 and $0.00738(\mathrm{~g} / 100 \mathrm{~mL})$ are added to the solution. However, above $0.0295 \mathrm{~g} / 100 \mathrm{~mL}$, the added $\mathrm{SrCO}_{3}$ crystals were not completely dissolved and crystallized in suspension.

Figure 3 shows the average grain size in the longitudinal direction of the obtained columnar crystals. In the figure, the case of $100 \mu \mathrm{m} \mathrm{SrCO}_{3}$ addition is shown in green, $30 \mu \mathrm{m}$ in blue and $0.3 \mu \mathrm{m}$ in red. Regardless of the average particle size of the added $\mathrm{SrCO}_{3}$, the particle size tended to decrease as the amount of solid $\mathrm{SrCO}_{3}$ added increased. The coefficient of variation (CV) of the crystals obtained under these conditions was in the range of $0.3-0.5$. This may be due to the fact that heterogeneous nucleation occurred with the increase in the number of crystals in the solution due to the increase in the amount of adding. Furthermore, the use of smaller particle sizes of added $\mathrm{SrCO}_{3}$ resulted in finer aragonite crystals when the amount of addition was equal. This may be due to the nucleation induced by the increase in the specific surface area of the solid $\mathrm{SrCO}_{3}$ in contact with the solution.

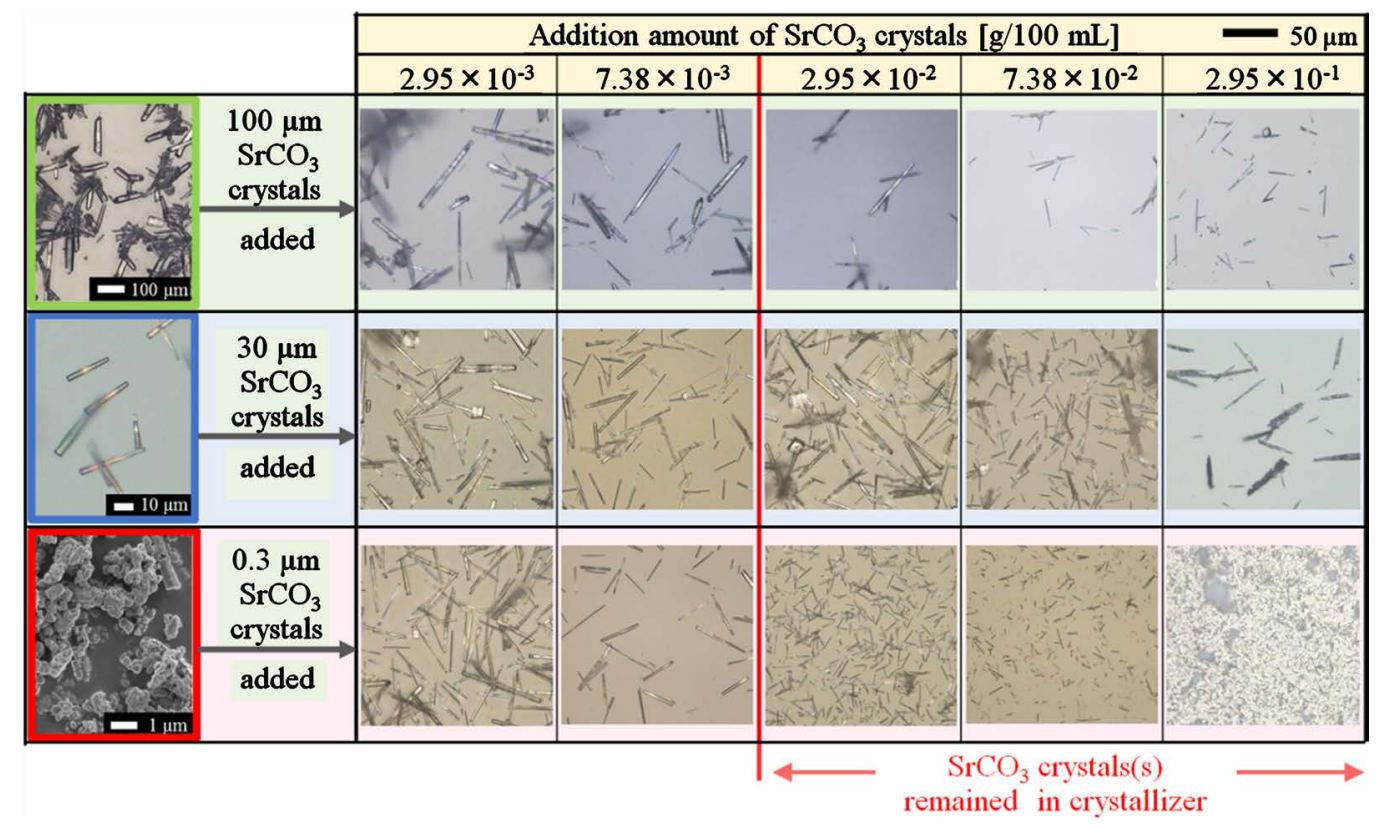

Figure 2. Optical micrographs and SEM images of $\mathrm{SrCO}_{3}$ crystals $(100 \mu \mathrm{m}, 30 \mu \mathrm{m}, 0.3 \mu \mathrm{m})$ and $\mathrm{CaCO}_{3}$ produced by adding various amounts of $\mathrm{SrCO}_{3}$ crystals. 
Figure 4 shows the aragonite content in relation to the amount of strontium carbonate added. The addition of $0.3 \mu \mathrm{m} \mathrm{SrCO}_{3}$ (red markers) resulted in higher aragonite content at all doses. When 30 and $100 \mu \mathrm{m} \mathrm{SrCO}_{3}$ was used (blue and green markers), the calcite content increased and the aragonite content decreased with increasing amounts of $\mathrm{SrCO}_{3}$ added (blue and green markers). The presence of small diameter strontium carbonate solids inhibited the formation of calcite and also allowed the refinement of aragonite.

Figure 5 shows the SEM and optical microscope images of $\mathrm{CaCO}_{3}$ crystallized with $2.95 \times 10^{-1} \mathrm{~g} / 100 \mathrm{~mL}$ of $\mathrm{SrCO}_{3}$. Figure $5(\mathrm{a})$ is an SEM image of the crystals obtained without the addition of strontium carbonate. The average particle size was $62.8 \mu \mathrm{m}$ and the coefficient of variation (CV) was 0.38. Figures 5(b)-(d) show that the addition of $0.3 \mu \mathrm{m}, 30 \mu \mathrm{m}$, and $100 \mu \mathrm{m}$ solid $\mathrm{SrCO}_{3}$ decreased the particle size of aragonite along with the decrease of strontium carbonate particle size, along with this average particle size. Furthermore, in Figure 5(b), cubic

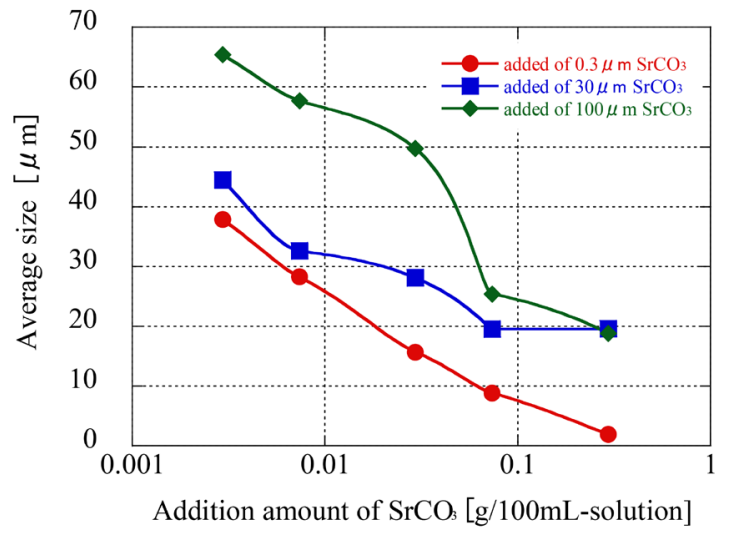

Figure 3. Addition amount of $\mathrm{SrCO}_{3}$ crystals [g/100mL-solution] vs. size of aragonite $[\mu \mathrm{m}]$.

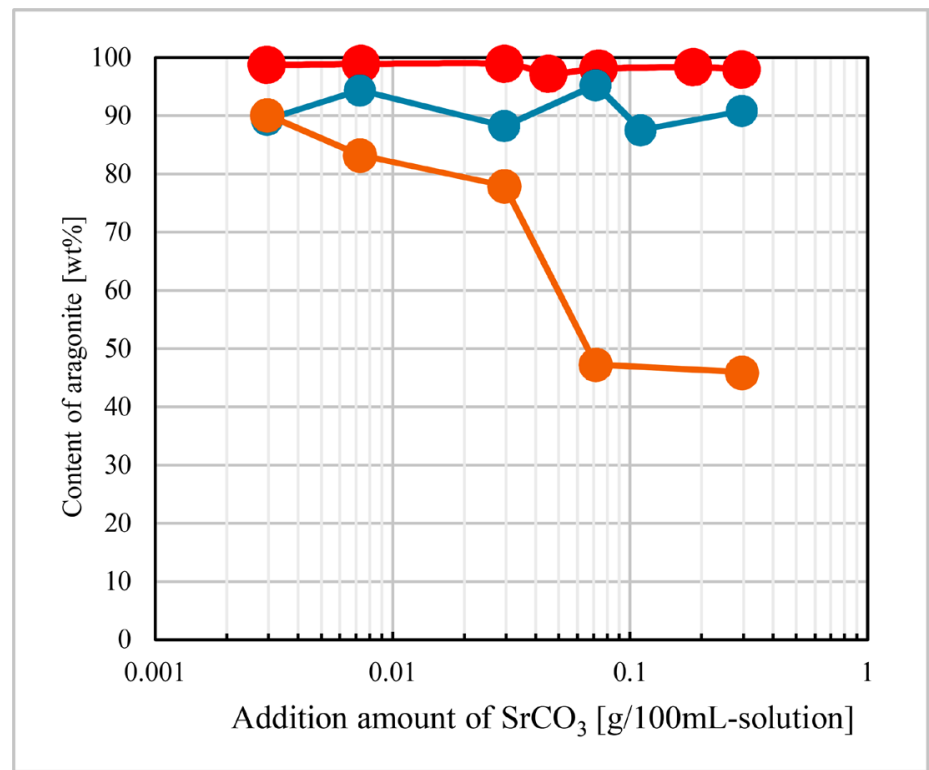

Figure 4. Addition amount of $\mathrm{SrCO}_{3}$ crystals [g/100mL] vs. aragonite content [wt\%]. 
particles were also observed, which also confirmed the formation of calcite.

\subsection{Elemental Analysis of $\mathrm{CaCO}_{3}$ after Crystallization}

Elemental analysis of $\mathrm{CaCO}_{3}$ crystals obtained with $0.295 \mathrm{~g} / 100 \mathrm{~mL}$ of $\mathrm{SrCO}_{3}$ crystals with the average grain size of $30 \mu \mathrm{m}$ and $100 \mu \mathrm{m}$ was performed by EDX mapping (Figure 6). In Figure 6, $\mathrm{Ca}$ is shown in red and $\mathrm{Sr}$ is shown in green, indicating that $\mathrm{CaCO}_{3}$ is formed around solid $\mathrm{SrCO}_{3}$. Furthermore, there is a difference in the crystal polymorphism of $\mathrm{CaCO}_{3}$ preferentially crystallized from the $\mathrm{SrCO}_{3}$ surface when the average particle size of the added $\mathrm{SrCO}_{3}$ is $30 \mu \mathrm{m}$ and $100 \mu \mathrm{m}$ in solid $\mathrm{SrCO}_{3}$. Columnar aragonite was frequently observed in the $30 \mu \mathrm{m}$ grain size of added $\mathrm{SrCO}_{3}$, whereas cubic calcite was predominantly observed in the $100 \mu \mathrm{m}$ grain size. When $0.3 \mu \mathrm{m} \mathrm{SrCO}_{3}$ was added, $\mathrm{CaCO}_{3}$ crystallization from the $\mathrm{SrCO}_{3}$ crystal surface could not actually be observed, but aragonite was inferred to be crystallized from the $0.3 \mu \mathrm{m} \mathrm{SrCO}_{3}$ surface.

$\mathrm{SrCO}_{3}$ has a structure similar to aragonite among the crystal polymorphs of $\mathrm{CaCO}_{3}$ [1] [2] [3]. Therefore, it is assumed that aragonite is susceptible to crystallization from all aspects of $\mathrm{SrCO}_{3}$, which is supported by the SEM images of the products and the high content of aragonite when $0.3 \mu \mathrm{m}$ and $30 \mu \mathrm{m} \mathrm{SrCO}_{3}$ were added. Calcite was preferentially crystallized at $100 \mu \mathrm{m}$ addition, which was
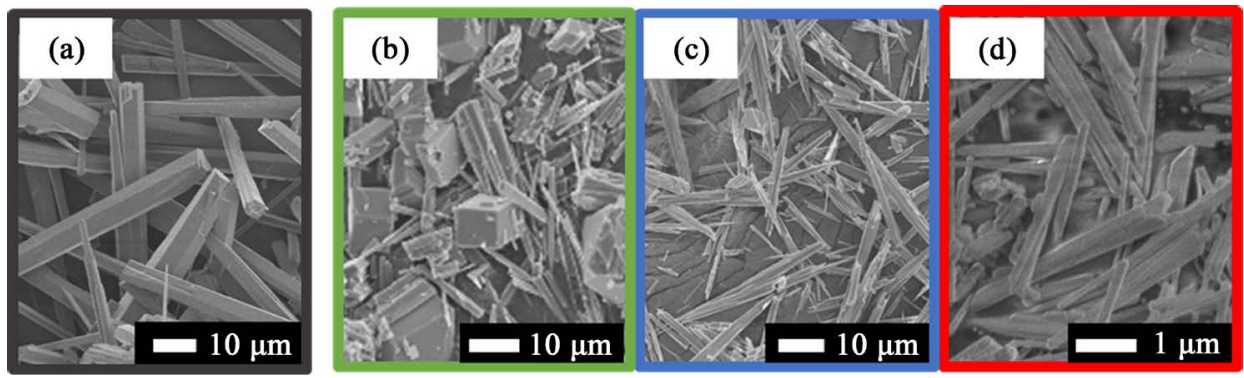

Figure 5. SEM images and optical micrographs of $\mathrm{CaCO}_{3}$ produced with $\mathrm{SrCO}_{3}$ crystals of 0.295 g/100mL: (a) without $\mathrm{SrCO}_{3}$ crystals, (b)-(d) with $\mathrm{SrCO}_{3}$ crystals $(100 \mu \mathrm{m}, 30 \mu \mathrm{m}, 0.3 \mu \mathrm{m})$.

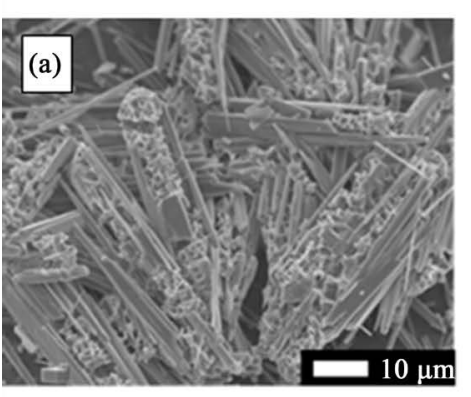

(b)

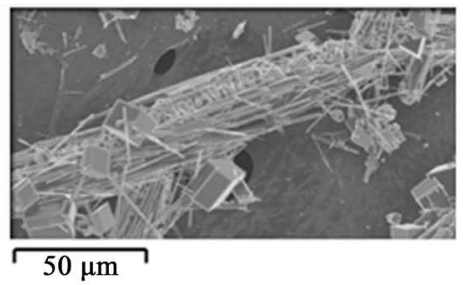

(c)

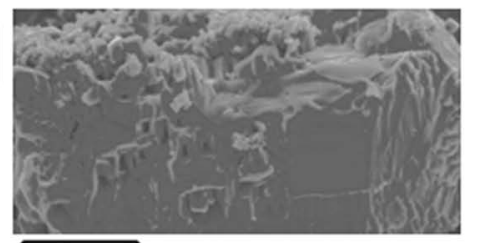

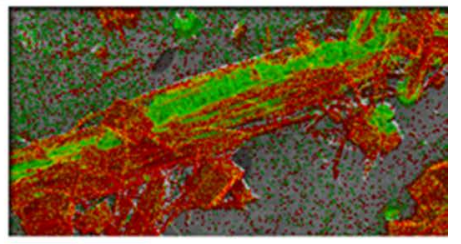
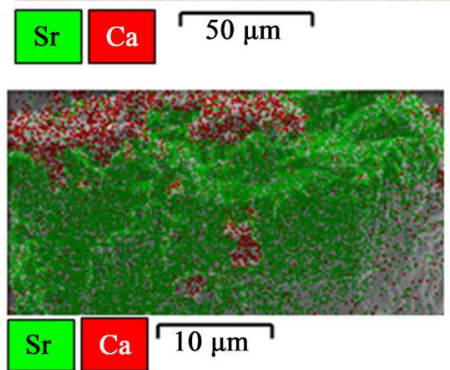

Figure 6. EDX mapping data of $\mathrm{CaCO}_{3}$ produced with $30 \mu \mathrm{m} \mathrm{SrCO}_{3}$ crystals ((a), (b)), with $100 \mu \mathrm{m} \mathrm{SrCO}_{3}$ crystals (c) at $0.295 \mathrm{~g} / 100 \mathrm{~mL}$. Green; Sr, red: Ca. 
attributed to the effect of the (220) plane found on the $\mathrm{SrCO}_{3}$ side, based on the crystal structure and crystal plane of $\mathrm{SrCO}_{3}[9]$.

\subsection{The Effect of Dissolved $\mathrm{SrCO}_{3}$ Addition}

The concentration of $\mathrm{Ca}$ ions in the initial solution and the rate of addition of the solution were changed and the images of the crystals formed are summarized in Figure 7. The crystal polymorphism of the obtained calcium carbonate differed depending on the initial solution and the drop operation. The polymorphism could not be controlled as $\mathrm{Ca}^{2+}(\mathrm{mol})$ in the initial solution produced aragonite, calcite, and satellite at $\geq 0.08$, while between 0.08 and 0.06 , vaterite, aragonite, and calcite were formed, and at $\leq 0.02$, aragonite, vaterite, and calcite were observed. However, only aragonite-type calcium carbonate with an average particle size of about $40 \mu \mathrm{m}$ could be obtained selectively when $\mathrm{Ca}^{2+}$ in the initial solution was $0.02-0.06 \mathrm{~mol}$. In the range of $0.02-0.06 \mathrm{~mol}$ of $\mathrm{Ca}^{2+}$, the aragonite with the largest average particle size was obtained at $0.03 \mathrm{~mol} \mathrm{of} \mathrm{Ca}^{2+}$ in the initial solution. This may be due to the fact that the initial concentration of $\mathrm{Ca}$ ions and the rate of addition could be adjusted to the supersaturation level, which promotes the selective formation of aragonite and crystal growth. The dissolved $\mathrm{SrCO}_{3}$ addition experiments showed that the crystal polymorphism could be controlled by controlling the supersaturation formation rate.

\section{Conclusion}

In calcium carbonate crystallization using the homogeneous urea precipitation method, the addition of solid strontium carbonate affected the crystal polymorphism and size of the calcium carbonate crystals produced, depending on the characteristics of the solid particles and the amount added. It was found that finer aragonite-type calcium carbonate crystals with a higher content were

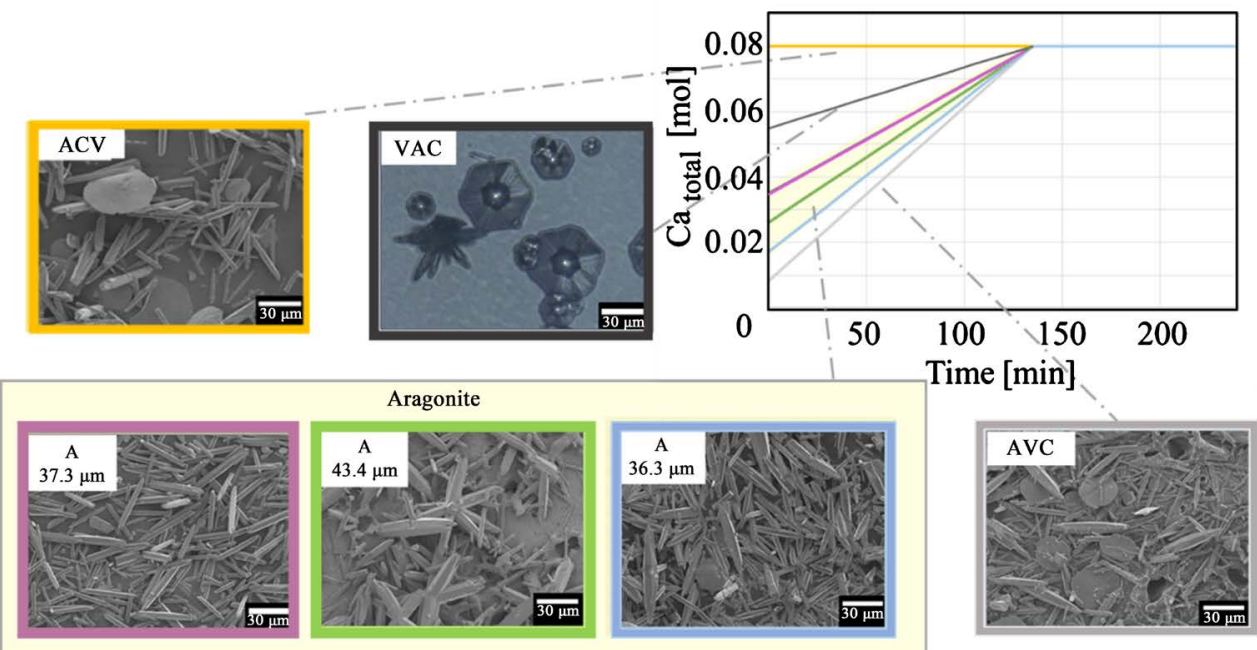

Figure 7. Time [min] vs. $\mathrm{Ca}_{\text {total }}[\mathrm{mol}]$ in crystallizer and SEM images and optical micrograph of $\mathrm{CaCO}_{3}$ produced with dissolved $\mathrm{SrCO}_{3}$. 
obtained when $\mathrm{SrCO}_{3}$ with a smaller average particle size of about $0.3 \mu \mathrm{m}$ was used. When strontium carbonate was added, the crystal polymorphism of the obtained calcium carbonate differed depending on the initial solution concentration in the crystallizer and the speed of addition. Especially, the selective preparation of aragonite was possible at the initial Ca concentration in the crystallizer in the range of $0.02-0.06 \mathrm{~mol}$.

\section{Conflicts of Interest}

The authors declare no conflicts of interest regarding the publication of this paper.

\section{References}

[1] Maslen, E.N., Streltsov, V.A. and Streltsova, N.R. (1993) X-Ray Study of the Electron Density in Calcite $\mathrm{CaCO}_{3}$. Acta Crystallographica Section B, 49, 636-641. https://doi.org/10.1107/S0108768193002575

[2] De Villiers, P.R.J. (1971) Crystal Structures of Aragonite, Strontianite, and Witherite. American Mineralogist, 56, 758-767.

[3] Le Bail, A., Ouhenia, S. and Chateigner, D. (2011) Microtwinning Hypothesis for a More Ordered Vaterite Model, Powder Diffraction, 26, 16-21. https://doi.org/10.1154/1.3552994

[4] Kojima, Y., Sadotomo, A., Yasue, T. and Arai, Y. (1992) Control of Crystal Shape and Modification of Calcium Carbonate Prepared by Precipitation from Calcium Hydrogencarbonate Solution. Journal of the Ceramic Society of Japan, 100, 1145-1153.

[5] Kojima, Y., Kawanobe, A., Yasue, T. and Arai, Y. (1994) Controls of Polymorphism and Morphology of Calcium Carbonate Compounds Formed by Crystallizing Amorphous Calcium Carbonate Hydrate. Journal of the Ceramic Society of Japan, $102,1128-1136$

[6] Wada, N. and Umegaki, T. (1993) Effect of Cation (Sr, Pb and Ba) on Calcium Carbonate Polymorphs under Diffusional Conditions. Gypsum \& Lime, 245, 211-219.

[7] Jyonosono, K. and Kato, A. (1995) Crystallization of $\mathrm{CaCO}_{3}$ from $\mathrm{Ca}\left(\mathrm{NO}_{3}\right)_{2}$ Aqueous Solution by Homogeneous Precipitation Technique Using Urea. Inorganic Materials, 2, 492-497.

[8] Jyonosono, K., Nagashima, S., Tsuchida, K., Maeda, H. and Kato, A. (1997) Effect of $\mathrm{Ni}^{2+}, \mathrm{Co}^{2+}, \mathrm{Mn}^{2+}$ and $\mathrm{Fe}^{3+}$ Ions on Crystallization of Calcium Carbonate. Inorganic Materials, 4, 238-245.

[9] Shirota, Y., Niki, K. and Shindo, H. (2011) Stabilities of Crystal Faces of Aragonite-Type Strontianite $\left(\mathrm{SrCO}_{3}\right)$ and Cerussite $\left(\mathrm{PbCO}_{3}\right)$ Compared by AFM Observation of Facet Formation in Acid. Journal of Crystal Growth, 324, 190-195.

https://doi.org/10.1016/j.jcrysgro.2011.03.033 